\title{
CHAPTER 12
}

\section{LEADERSHIP AND EXECUTIVE MANAGEMENT}

\section{Principal authors:}

Julia Miranda Londoño, Jon Jarvis, Nik Lopoukhine and Moses Wafula Mapesa

\section{CONTENTS}

Introduction

- Leadership

- Executive management

- Executive management: Working with people

- Conclusion

- References

IUCN 5 WCPA 


\section{PRINCIPAL AUTHORS}

JULIA MIRANDA LONDOÑO is Director-General of the National Parks Service of Colombia and a Regional Vice-Chair for South America of the International Union for Conservation of Nature World Commission on Protected Areas (IUCN WCPA).

JONATHAN JARVIS is the Director of the US National Park Service.

NIKITA LOPOUKHINE is a former chair of the IUCN WCPA and was recently honoured with the J. B. Harkin Award for his lifelong commitment to Canadian conservation.

MOSES WAFULA MAPESA is a former chief executive officer of the Uganda Wildlife Authority, and is currently the Regional ViceChair for the IUCN WCPA for Eastern and Southern Africa and a board member of Leadership for Conservation Africa.

\section{ACKNOWLEDGMENT}

Appreciation is expressed to Andre Sovinj for his contribution to this chapter.

\section{CITATION}

Londoño, J. M., Jarvis, J., Lopoukhine, N. and Mapesa, M. W. (2015) 'Leadership and executive management', in G. L. Worboys, M. Lockwood, A. Kothari, S. Feary and I. Pulsford (eds) Protected Area Governance and Management, pp. 353-380, ANU Press, Canberra.

\section{TITLE PAGE PHOTO}

Mount Everest, 8848 metres, Sagarmatha National Park, Nepal: the highest point on the Earth's surface and a World Heritage property

Source: Ian Pulsford 


\section{Introduction}

\section{Julia Miranda Londoño}

This chapter addresses a subject that in principle might appear not to have a direct relation with protected areas because its scope normally refers to private business administration or public affairs. Nevertheless, it is absolutely clear that now, more than ever, strong and firm leadership is essential to achieve the effective conservation of protected areas around the world. Leadership is required in order to direct the course of the institution in charge of protected area management. It is also required for planning, for providing direction, for guiding and inspiring protected area staff and for defining and promoting conservation. It is also necessary in order for people to understand why protected areas are essential for the development of countries, the wellbeing of people and the health of the planet. Leadership is also required for working with other sectors of the economy, as well as with local and national governments and the media, so that they understand the role of conservation and thus support it within their own capacities and responsibilities.

Our planet is quickly changing. It is thus necessary for those responsible for exercising leadership in the conservation of the environment and biodiversity to abandon old criteria and to be more creative and willing to take risks in designing strategies that influence the public, thus bringing them closer to nature. This will allow us to achieve an efficient response for its protection and conservation. A world authority on leadership, Ronald Heifetz, who is Director of the Leadership Education Project at Harvard University's John F. Kennedy School of Government, says the new role of a leader is changing for the better. This new role is to help people face reality and to mobilize them to make change' (Taylor 1999). Taylor (1999) notes that in making change—and again quotes Heifetz-'[p]eople are afraid that they will lose something that's worthwhile. They're afraid that they're going to have to give up something that they're comfortable with.'

Heifetz recognises the challenges of leadership along with the pain of change, but he says this:

shouldn't diminish anyone's eagerness to reap the rewards of creating value and meaning in other people's lives. There's a thrill that comes with the creation of value - and of course there's money and status-and those rewards are surely worth the pain that comes with the territory. There are lots of things in life that are worth the pain. Leadership is one of them
... The real heroism of leadership involves having the courage to face reality-and helping the people around you to face reality. (Taylor 1999)

He develops many interesting ideas applicable to protected area management. Heifetz states:

[L]eadership means influencing the organization to face its problems and to live into opportunities ... mobilizing people to tackle tough challenges ... is what defines the new job of the leader ... At the highest level, the work of a leader is to lead conversations about what's essential and what's not. (Taylor 1999)

These leadership matters are discussed in this chapter. Three highly qualified chief executive officers (CEOs) of protected area agencies from different parts of the world have contributed their thoughts and lessons learned in very personal accounts. Each CEO has played a major role in the 21 st-century history of protected areas in their own country and the conservation of protected areas worldwide, so we are indeed privileged to receive the benefit of their insights here. This is a different approach to what you will find in more traditional textbooks about leadership. Here you will 'hear through words' the lived personal experience of each CEO as they present their section, for each has lived and worked in protected areas all of their careers and each has been happy to tell their story and pass on their lessons learned.

At the time of writing in 2014, Jon Jarvis is the Director of the US National Park Service (NPS); Nikita Lopoukhine is a former director-general of Parks Canada; and Moses Mapesa is a former CEO of the Uganda Wildlife Authority (UWA). We have presented their accounts of leadership and executive management for their organisations as three parts to this chapter that cover two functional areas. They reflect important lessons learned while they worked in their protected area organisations. Brief context-setting statements for the organisations for which they worked are also included in each section (Boxes 12.2, 12.3 and 12.4). Background on my own organisation is given in Box 12.1.

We have divided this chapter into three main parts that deal with two protected area themes: 'leadership' and 'executive management'. The reason for this division, in Jon Jarvis's words, is that ' $[\mathrm{f}]$ rom my experience, there is a distinction between leadership and management. Leadership is about inspiration, vision and strategic decision-making. Management is about working with budgets, staff, teams, and the day-to-day operations of a protected area.' To best serve our protected area community, this chapter will 


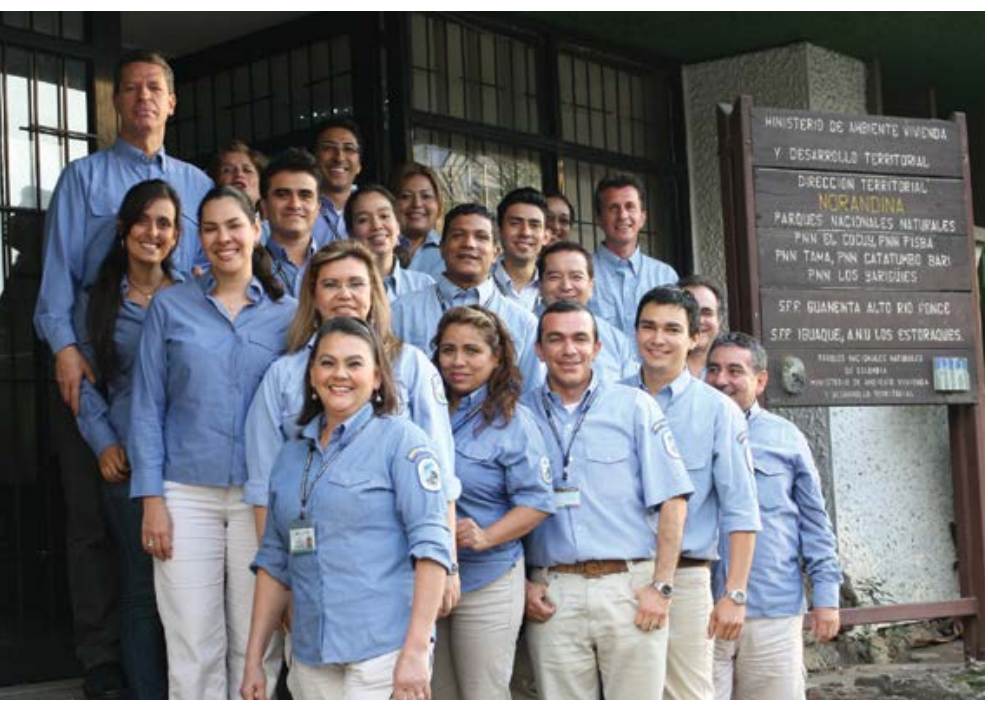

Some staff of the National Parks Service of Colombia Source: National Parks Service of Colombia

\section{Box 12.1 National Parks Service of Colombia}

The National Parks Service of Colombia is a government agency, administratively and financially autonomous under the political mandate of the Ministry of Environment and Sustainable Development. The agency as such was created by law in 1993 (the first Colombian national park was declared in 1960) as an administrative unit of the National Environmental System (Law 99 of 1993), aimed at managing the areas in the national parks system and coordinating the national system of protected areas, to conserve in situ the biological and ecosystem diversity of the country, provide and safeguard environmental goods and services, protect the cultural heritage and natural habitats of traditional cultures and contribute to sustainable human development. The National Parks Service is directly in charge of managing 59 protected areas, and articulates the basic management criteria for 440 protected areas at the regional and local levels, including private areas and forest reserves. With an overall budget of US\$33.3 million and 1250 full-time staff, the National Parks Service protects 14269644 hectares, which is 9.98 per cent of the terrestrial land area of Colombia and 1.48 per cent of the marine territory.

address both, but separately, so the reader can understand that it is possible for one to be an excellent manager, but not a great leader, or an excellent leader and not a good manager. A career progression in protected areas often begins with management and turns to leadership. In small protected areas, one person can do both, but in large areas or at the CEO level, these duties are often divided (as they should be). The CEO needs to either split their time appropriately between leadership and management or delegate the role of management to a deputy or team of assistants.

In the first part of the chapter, Jon Jarvis describes leadership of the NPS, one of the world's largest and oldest government protected area organisations. In the second part, under the theme of executive management, Nik Lopoukhine describes his thoughts and experiences about operating at the highest executive management levels in Parks Canada and elsewhere; and in the third part, Moses Mapesa presents his account of working with people based on his experiences as the CEO of the UWA. Moses's account is also under the theme of executive management. His account of his rewarding and turbulent experience as a CEO is compelling and it is an important lesson for all concerning personal integrity and courage that have succeeded over the corrupt behaviour of others.

Each of these three accounts is different-it is situational and personalised-but there are some very important CEO leadership messages for protected areas that are recurring, and we provide a concluding section in which we reflect a little on these matters by providing guidance for the future. What is particularly important in the rapidly evolving world of protected area management is that this chapter is about the executive leadership of protected areas, for protected areas and by experienced protected area chief executives.

\section{Leadership}

\section{Jon Jarvis, Director, US National Park Service}

\section{Concept}

We who serve as leaders of the world's protected areas are in the perpetuity business. There is much written about leadership in the private sector but far less about leadership in the public sector and even less about leadership of protected areas. Unlike private sector leaders who provide products and services to the public over a given time frame, our working assumption is that society will always need protected areas and our decisions must consider the long-term conservation and preservation of the resource and the benefits to the general public. Our stewardship is carried out on behalf of the trust placed in us by the public; therefore they deserve the very best leaders and managers. This chapter is specific to the qualities and attributes of great leaders of protected areas. 


\section{Attributes of a leader}

Leadership of protected areas, first and foremost, is based on core values of conservation and preservation. Without a deep and abiding belief by the leader that conservation and preservation are essential to our survival, all decisions will be seen as shallow and motivated by external factors. The leader must also have vision that things can and will get better through their work. Optimism is essential to effectiveness, especially since we know that protected areas will rarely have the level of funding and staffing that we believe they deserve. Perseverance is also essentialpursuing each threat or opportunity with patience and a dogged determination to succeed. Unfortunately, no leader of a protected area is armed with the complete science, past experience with the issues or a sage-like ability to see outcomes. Instead, the leader requires a certain comfort with ambiguity. A great leader is an excellent communicator of his or her ideas, vision, commitment and optimism. A great protected area leader inspires others both within and outside the organisation to take action. A great leader sees all the parts interacting and puts them into a strategic plan that results in marked improvement of the effective protection of these legacy lands. A great leader encourages innovation and creativity. He or she can navigate the treacherous waters of politics, knowing when to give in and when to push back. Lastly, protected area leadership is lonely, and while a peer network is important, one must develop the self-confidence to defend the protected areas when outnumbered and overwhelmed.

There is no greater calling than to be a great protected area leader, as they give a voice to those who cannot speak for themselves, a voice to those of the past who handed us this responsibility, a voice to the animal and plant kingdoms with whom we share the Earth and a voice to future generations, who are counting on us to leave them a world in which they will want to live.

\section{Leadership and ethical values}

Protected area conservation leadership is a public trust carried out for the benefit of all people, not just some of the people; therefore, ethical behaviour by the leader is essential to success. In addition, unlike many other jobs, the ethical value of conservation leaders continues 24 hours a day, seven days a week, and 365 days a year, on and off duty. Any leader who is working in conservation or preservation can fully expect that those who oppose his or her efforts will at some point attack the leader's personal integrity. If they cannot destroy your policy, they will try to destroy your reputation and, by doing so, undermine your initiative and effectiveness. If they find

\section{Box 12.2 US National Park Service}

The National Park Service (NPS) is a bureau of the US Government within the Department of the Interior. With a full-time staff of 25000 , approximately 10000 seasonal staff and hundreds of thousands of volunteers, the NPS is the steward of more than 32 million hectares in 401 national parks, monuments, historical sites and recreation areas in every State and Territory of the United States. The NPS hosts 280 million visitors to these parks annually, with an operating budget of US\$2.8 billion. The NPS has additional program and grant responsibilities for historic preservation and recreation in communities throughout the country. The NPS will be 100 years old in 2016 and is preparing for its second century of stewardship and public engagement.

any departure from the highest standards, even in an offduty status, it will be used against you. At the end of your term as a protected area leader, even if you lose some battles, you must never lose your integrity. The leader also sets the tone of ethical behaviour for all employees. If the leader displays unethical behaviour, it will be impossible to expect higher standards of subordinates.

\section{The ability to promote enthusiasm}

Author and famous US conservationist Aldo Leopold said that to have an ecological education is to walk in a 'world of wounds' (Leopold 1993:165). At a meeting of biologists and historians, discussing the impacts to natural and cultural resources from climate change, a biologist commented that at least the cultural professionals had a method to document a doomed resource and to say goodbye. There is, however, no equivalent process in the natural resource field. It is not uncommon to see depression and low morale in staff who work in the conservation field. Therefore it is essential that the leader conveys a sense of optimism and enthusiasm. This can be accomplished by the leader demonstrating honest interest in the detailed work of the employees and celebrating success, no matter how small. Spending time with each employee, regardless of their level within the organisation, can convey to them a sense of worth. It is also important for the leader to focus attention on the wins rather than the losses. One area of positive impact is in the restoration of habitat for a locally extirpated species. Such restoration of a natural resource can also restore enthusiasm and morale. There are no more enthusiastic users of the outdoors than children, whose sense of wonder is infectious and can be contagious. For the 373 383-hectare Olympic National 
Park in Washington State in the western United States, when staff were ready to release a population of 'fishers' to reintroduce them to this north-western forest, the NPS team allowed high school students to do the release and soaked up their excitement.

\section{Excellence in communications}

A great leader is also a great communicator. The leader does not have to know everything about an area, issue or topic, but they must be able to communicate key components to various audiences. The style, depth, delivery and tone of the leader's communication must be tailored to the different audiences. Speaking to an elected representative is very different to speaking with an indigenous leader. The key to becoming a great communicator is first to watch and emulate those who do it well and second to practise, practise and practise. Take a hint from the great comedians: they practise their routines over and over in front of live audiences until they get it right. As an NPS field manager, particularly in rural communities, I always made sure that I reached out to community leaders long before there was a crisis that required me to do so. Early establishment of open communications will lead to much better relationships when there are issues to resolve. Crises require more frequent communications than normal.

\section{Teamwork}

The days of command and control are long gone, as are the days of the heroic leader. The best accomplishments are the result of effective teamwork. There are many books on team development, function and effective management, and I would recommend any leader who works with a team researches the literature on team dynamics. Below are some of the guiding 'nuggets' or lessons I have gleaned and successfully applied.

- Assemble a team of people who want to work together and who have complementary skills.

- Aim for diversity and a diagonal cross-section of the structure of the protected area organisation.

- Give the team a meaningful task and clear goals, but be careful not to dictate the process by which they will work. Telling them not only what but also how will inhibit both creativity and team function.

- Keep it small. Teams which are expected to make decisions should have between six and 10 members. Larger teams have difficulty reaching consensus.

- Observe the team's interactions and prevent one voice from dominating. Create space for the minority voice on the team so that all voices are heard.
- Look for early wins by the team and reward success; then increase their challenges.

- Take their advice and use it. If you do not then you are wasting their time and talents.

- If the issue is field based, take the team to the site and have the discussion on the ground.

\section{Strategic decision-making}

The ultimate role of a leader is to make the final decision. The three most important components of good decisionmaking are as follows.

1. Use the best available sound science and other scholarly information. Note that this is the 'best available', which implies that the science may be incomplete but it is still informative and relevant. Also note 'sound science' implies peer-reviewed, published or well-documented information.

2. Maintain accurate fidelity to the law. We operate within a body of law and policy and a great leader must understand the legal foundation of those laws, as well as the letter of the law. Deviation from fidelity to the law puts the decision and the resource at risk.

3. Act in the long-term public interest. Given we are in the 'perpetuity business' with protected areas, decisions must be based on the long-term view of what is in the best public interest and must not be made for short-term political expediency.

These principles establish the foundation for making decisions. The leader must also have a strategy for making a decision stand the many tests it will be subjected to. Remember that 'sunlight is a great disinfectant' or, in other words, the decision must withstand the scrutiny of the public and therefore must be made in the open, not behind closed doors. It also must be consistent with policy, past practice and other decisions made in similar circumstances. If there is significant deviation from these principles, the leader must be able to clearly explain the reasoning behind the discrepancy.

\section{Dealing with change}

As they say, the only constant is change. Public opinion, demographics, economics, funding, politics and the climate are all changing. The leader must be able to monitor and keep abreast of these and communicate effectively to various constituencies, especially employees and partners. Great leaders can use change to their advantage to make strategic, positive corrections 
recreational parks and protected areas as components of their community protection. When these investments are geographically linked, ecosystem function can be restored and native species can thrive.

\section{Perseverance}

On the high, windblown ridges of the Great Basin National Park in Nevada, western USA, stand the gnarly trunks of bristlecone pines (Pinus spp.). Some individuals are 5000 years old and have been growing in that spot since before the first pharaoh ruled Egypt in 3000 BC. From such grand old trees, we can draw our inspiration for perseverance. Nature perseveres in spite of human efforts to subjugate it. In addition, the wonderful thing about nature is that, given a chance, it can recover as well. Great leaders have the ability to persevere in spite of significant setbacks, because they are in it for the long term.

\section{Restoration at Elwha River}

Choices of direction: protected area, Taiwan. Typically, strategic decision-making is not simple and requires the three components of good decision-making described above

Source: Graeme L. Worboys

to the organisation, its policies or even its structure. For instance, a shrinking economic environment presents an opportunity for more collaboration and innovation within the organisation. One major challenge for leadership in the world of conservation is that climate change is affecting our protected areas in ways we do not completely understand. It is therefore essential that we begin to plan for that change and allow for multiple futures, while building as much resilience into the system as possible.

\section{Creative solutions for change}

Since we know that change is inevitable, as leaders, we need to embrace it. Great leaders articulate a vision and use change as an opportunity to drive towards that vision. Let us take the example of sea-level rise affecting coastal protected areas. A simple question would be which area is going to be the next coastal wetland created by the new sea-level, and to ensure that area, if possible, is included within the protected area's boundaries via acquisition. This could ensure that the coastal environment will have the resiliency to withstand sea-level rise. Likewise, rising sea-levels and increased storm surges are beginning to show that 'green infrastructure' such as mangroves may be far more resilient and sustainable than traditional 'grey infrastructure' such as seawalls. This can then result in major investments by coastal communities in open space,

It is also useful to reflect on the need for perseverance as a leader. Some projects take decades of leadership to achieve success. One such project with which I have been involved for more than 20 years is the removal of two dams on the Elwha River. This river drains 181 square kilometres of pristine habitat within Olympic National Park and then hits two hydroelectric dams before flowing into the Pacific Ocean. More than 100 years ago, the river was the lifeline for hundreds of thousands of salmon and was the lifeblood for the Lower Elwha Klallam Native American tribe. Work by a team over 20 years means the dams are now in the process of being removed, completely reopening the park again—after 100 years - to the return of various species of salmon and steelhead (Oncorhynchus mykiss irideus), another species of fish. Persistence, patience, partnerships, consistency and continuity have achieved what many thought was impossible. My personal involvement has been on and off during the entire period, with a key leadership role for 10 years as regional director of the region that oversees Olympic National Park and director of the entire NPS. This has required me to secure nearly US $\$ 350$ million in funding for the project, overcome periodic opposition, shore up fragile partnerships, work with politicians, select contractors, celebrate successes and hire new people to lead the park-all the while doggedly keeping my eye on the ultimate goal of dam removal. This has been an extraordinary team effort. 


\section{Building supportive networks}

The management of protected areas through networks is an emerging field, and this concept can be applied to the land itself and to the organisation. At the landscape scale, networks of interconnected protected areas can create corridors for wildlife and build long-term resilience into the ecosystem. Like an organisational ecosystem, great leaders develop a network of support, advice and counsel over time, which they can rely on when faced with a daunting issue. They may not know the answer, but they know whom to call. They also reciprocate when given the chance. Protected area networks also include partners, other agencies, local communities, volunteers, advocates and visitors, all of whom contribute to the long-term vision. Great leaders build and nurture these networks.

\section{Managing organisational change}

Organisational change is difficult and the leader must devote enormous personal effort to accomplishing significant positive change. Before any major organisational change is attempted, a leader must selfassess their own commitment and capacity to see it through. First, the leader must communicate to the employees why change is happening, whom it will affect and when. The best leaders take on board feedback and accumulate input into alternatives to accomplish the objectives. Once the direction is decided, the leader must stay involved and abreast of the reactions. Frequent communication is essential. An assessment of the results and a commitment to review and correct mistakes must also be honestly made.

\section{Innovation}

Innovation is essential to any protected area organisation in that the challenges constantly require new ideas. Well-respected author and organisational consultant Margaret Wheatley (2006) concluded that innovation and creativity already exist in any organisation and it is the responsibility of leadership to find it, highlight it, nurture it and it will grow. Great leaders embrace this focus on innovation and create a space in which innovation and creativity can flourish. Leadership then selects which innovation should be nurtured and therefore the direction of the organisational change driven by this innovation.

\section{Investing in new ideas and new systems}

New ideas are a great way to adapt the organisation to change and new systems are important additions to accomplishing the work. That said, all new ideas need to be tested and new systems can be expensive, timeconsuming and a distraction from the core work. Great leaders encourage new ideas, but field test them before imposing them on the full organisation.

\section{Communication and advocacy}

Protected areas need advocates, and great leaders know how to nurture and communicate with key advocates and advocacy organisations. Great leaders are by their nature also advocates for the protected area, for the resources within and for their staff and partners. Advocacy is, however, a carefully honed skill. In some countries, 'advocacy' organisations have a special legal status and can be party to litigation. Great leaders learn to walk a fine line between their own advocacy and that of the outside advocate. When communicating with advocacy organisations, the leader must show both passion and restraint.

\section{Protected area messages for life's sake}

Issues as important as conservation and the management of protected areas should never be reduced to a soundbite. That said, the public loves a catchy phrase and can be motivated by them. Leaders of protected areas who use these types of messages must be able to go deeper into the meaning behind them or the phrase will soon lose all appeal.

\section{Dealing with community protests against key conservation decisions}

It is not uncommon for a decision regarding a protected area that is made for the good of all the public to also restrict an activity undertaken by the local community. This is particularly problematic when it restricts a traditional activity that may have been done for generations, but now has been recognised as having a significant impact on the purposes and values of the protected area. First and foremost, the great leader must do everything in his or her power to engage the community before they resort to public protests. At all costs, do not let the protest be about a lack of engagement with the community, but rather about the decision itself. One of my favourite quotes is from a mentor of mine, who used to say 'any idiot can say no; it is a lot harder to get to yes'. Any protected area leader can gauge when an 
issue will result in a negative response by the community, so with that knowledge, it is necessary to engage with the community to find where there is common ground. For example, a great leader must be able to explain the rationale of a decision that is going to restrict a community's activity but provide some other benefit such as an increase in the overall economic benefit to the community because more visitors will be attracted or because the environment or ecosystem services will be restored to provide a healthier environment.

\section{Defining an issue}

An old mentor of mine always said 'how you see things depends on where you stand'. It is one of the prime responsibilities of leadership to be able to define all the pertinent elements of an issue-the science, the politics, the practicality, the history, the public opinion, the risk and the legal ramifications - and put them into context. This process is done by bringing all the experts on this issue into the same conversation and giving each one the opportunity to speak openly and honestly. Issues that are unclear need to be assigned to someone to conduct further analysis and bring it back to the group. On any issue there are often strong opinions on all sides. It is the responsibility of the leader to ensure all opinions are heard. Spend time trying to discern what you know and what you do not know. Great leaders seek out those who have opposing opinions on an issue and listen to their views even when there is disagreement.

\section{Defining the consequences of no action}

No action or no decision 'is a decision' because the resources we manage are not static, they are not frozen in time and procrastination or delay only allows the present to continue, often with unintended consequences. In addition, the longer an activity that is incompatible with the purposes of a protected area is allowed to continue, the harder it will be to eliminate or restrict. 'No action' over a long period allows incompatible activities to become standard practice and acceptable — and almost impossible to alter. There are times when no action is appropriate but it always must be viewed in the same light as a decision rather than just procrastination or an inability to make up one's mind.

\section{Describing with clarity the response needed}

The role of the great leader is often to bring clarity to an issue so that the actions are obvious to all. The key is to listen intently and articulate the core or essence of what you have heard. The leader must then coalesce all of the input into a clear vision of the direction needed to resolve the issue. Very few leaders can do this without a great deal of practice and experience with complex issues. With practice, leaders can become very good at this essential task. If the decision or response is complex, the leader must be very specific as to what needs to be the next step, who is going to do it and when. Orchestration of the response can be as important as the decision itself.

\section{Securing support of politicians}

Politics is a reality that every protected area leader must learn to live with, embrace and use effectively. Some politicians operate under the principle that virtue and public service are their own reward' and these are the easiest to work with because of the intrinsic value found within protected areas. That said, all politicians are driven by several factors: the desire to be re-elected by their constituents, taking credit for accomplishments and positive media attention. Protected areas can effectively deliver all three. The first step is to build a working relationship with a politician so that you may contact them directly when there is an opportunity for them to be seen by their constituents doing something positive, when there is an announcement they can take credit for or when there is positive media attention from an event or action at the protected area in which they can participate. Offering this kind of opportunity will build the support needed when there are tough political issues and when you need them to stand up for protected areas. There is no room for corruption, back-room deals or special considerations for politicians, their friends or colleagues. Compromise of the integrity of the leader or the protected area for the benefit of a politician, no matter how powerful, should never be considered.

\section{Anticipating and planning media interest}

Like politics, the media is a part of our lives. Every protected area should have at least one person who is trained to work with the media, write press releases and be on the scene with reporters and their cameras. The media is interested in good and bad stories, interesting sidelines, scary stuff and human interest, especially interesting characters. Protected areas have all of these stories. The media will want to talk to the 'leader' of the protected area and great leaders are always willing to talk to the press. This is an area where practice makes perfect. Do not be afraid to go in front of the camera. Critique your performance brutally. Look at everything from the clothes you wear to the way you look at the reporter, to the confidence used in your answers. If the reporting area has traditional media, as 


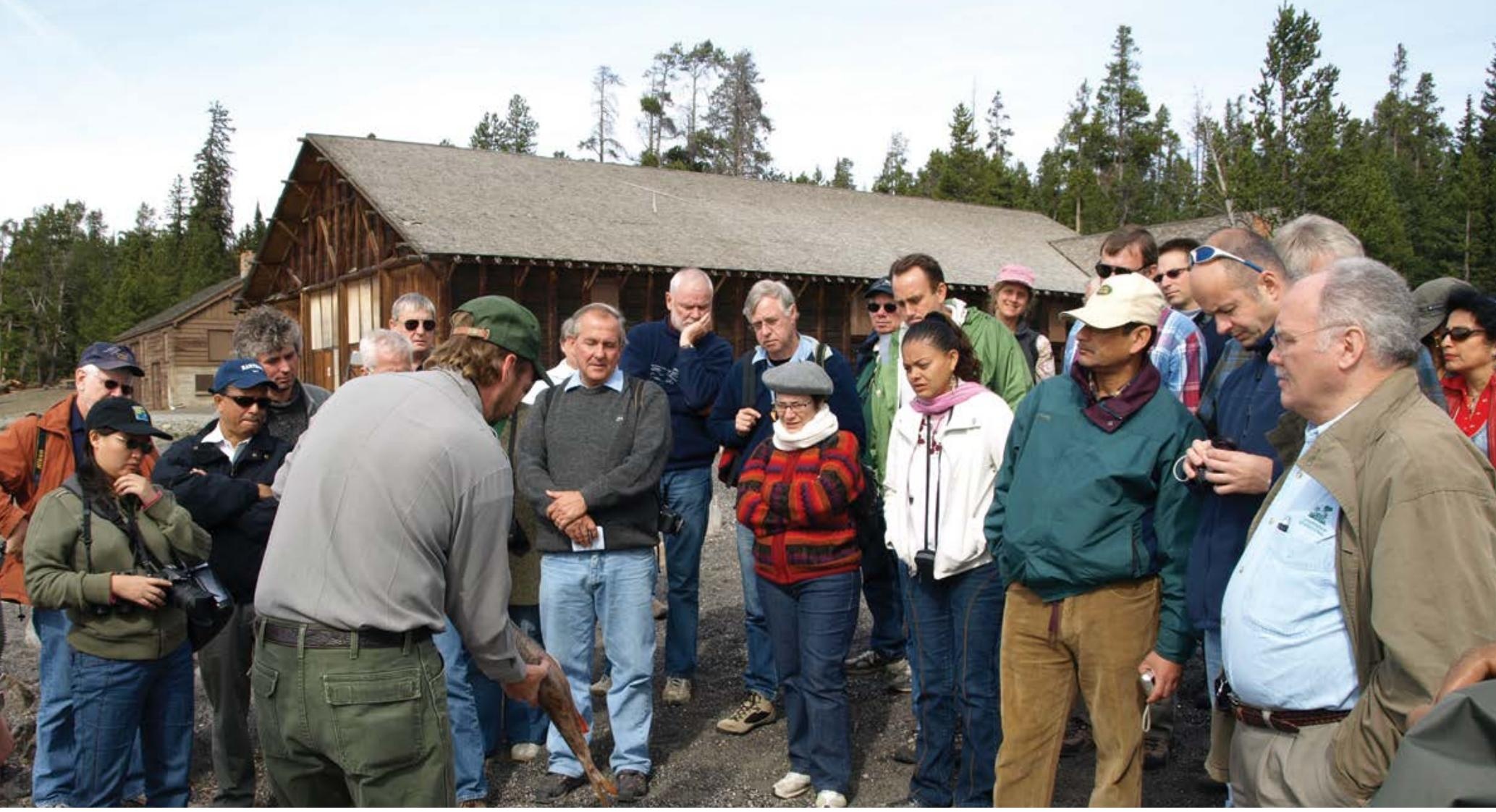

US NPS researchers briefing protected area management leaders from around the world about their research and advice for management in relation to introduced fish, Yellowstone Lake, Yellowstone National Park, USA

Source: Graeme L. Worboys

in newspapers, radio and television, a relationship can be built so that 'scoops' can be granted to specific media. Develop a relationship with the reporter who frequently covers activities in the protected area. Invite them out at slow times so they get a sense of the protected area's operation and its complexity. Push stories to them that you think they will like. Hold press conferences when issues are complex and controversial and take questions, answering them honestly. Never attack the media itself, as that is a losing proposition.

\section{Securing action to achieve conservation outcomes}

Essentially this is the crux of the matter. As leaders, we must have a strategy to accomplish our conservation goals. Nature needs us, as there are many forces, from climate change to extractive industries, which, without our active engagement, could have a negative impact on the protected areas within our stewardship. A great leader combines all the elements of science, media, politics, staff effort, community support and public engagement into a series of strategic actions that result in a positive outcome for protected areas and for the long-term view of the public interest. There can be few greater callings.

\section{Executive management}

\section{Nikita Lopoukhine}

\section{Concept}

Protected area agencies consist of a headquartersnormally near the seat of government - and a system of geographically dispersed protected areas. Communication can be instantaneous in the 21 st century, which permits issues to be dealt with collectively. Each component of the agency is faced with unique situations and different stakeholders. Executive managers must be equipped to deal with issues as they emerge locally while also being cognisant of global, national and regional-level interests. This is the common reality of each executive manager of a protected area agency, which includes the CEO through to the superintendent of a protected area. To be successful, protected area executive managers must have interpersonal and personal skills that include clear communication. Armed with such skills, a manager is well served in the planning and the realisation of both short-term and long-term strategies. 


\section{Attributes of an executive manager}

\section{Inspirational leadership}

Jon Jarvis has described CEO leadership earlier in this chapter. It is a quality that every successful executive manager has and, while easy to dissect, it is not so much taught as being an acquired skill. Demonstrated leadership is inspirational to staff. Characteristics of decisiveness, fairness and strategic leadership instil confidence in those who work with and report to executive managers. To be sure, a manager's responsibilities can be difficult, as they often face decisions that, in extreme circumstances, may affect the lives of people. Where possible, the manager must be open to the views of people and consider the concerns and interests of those affected; however, the final decision is his or hers.

\section{Communicating with people}

Protected areas, whether private or public, are run by people, depend on people and, as a societal construct, are for people. While a principal objective of a protected area is to conserve biodiversity, success is dependent on the ability to manage people. Management of people is undertaken through the communication of ideas, plans and the regulatory regime. Internal protected area agency communication is as critical as external communication. A successful executive manager devotes time and effort to communicating with employees. This is critical to ensure that agency employees are apprised of common objectives, purposes and intentions. In turn, frontline staff can instil an understanding among stakeholders of the values of and the plans for protected areas. Hence, it is paramount to invest in the development of communication skills for both the executive manager and the frontline staff.

\section{Listening}

Communication is a two-way skill. Using a variety of media to push one's views is not valid communication. If there is not an equivalent effort devoted to listening, communication will inevitably fail in delivering the results that are wanted. Listening encompasses opportunity for feedback and responding to the feedback. Indeed, responding signals that one has been heard.

\section{Negotiation skills}

Along the way to making decisions, executive managers negotiate through alternative and in some cases conflicting views. The decision needs to account for the source of the views while keeping track of the overall strategic direction and overall plans. Political

\section{Box 12.3 Parks Canada}

Parks Canada is an agency of the Government of Canada, under the responsibility of the Minister of the Environment, who mandates it to 'protect and present nationally significant examples of Canada's natural and cultural heritage, and foster public understanding, appreciation and enjoyment in ways that ensure the ecological and commemorative integrity of these places for present and future generations' (Parks Canada 2012:5). Parks Canada manages 44 national parks (including seven national park reserves), four national marine conservation areas, one national landmark and 167 national historic sites. The annual budget for Parks Canada is approximately US $\$ 450$ million and the agency has 4000 employees, a large number of whom are seasonal.

interests and the views of labour unions are perhaps the most difficult to negotiate. Political masters are at times indifferent to the reality of policy, legislation and approved long-term plans. Likewise, unions may have a greater agenda than the immediate benefits accruing to protected area employees. In addition, a business owner whose business may be compromised by a new protected area plan is equally difficult to convince of the benefit of such a plan. To get through such situations and arrive at a decision that is supportive of the overall strategic direction of the agency use communication skills, clarity of purpose and be open to solutions that can assuage the union, the politician or the business owner with whom one is negotiating.

\section{Conflict resolution}

Negotiations lead to solutions but along the way conflict can occur. This can happen when differences perceived by one or both parties are viewed as threatening to their interests. New ideas, different approaches and methods, and change in responsibilities can all lead to conflict. Much has been written on how to resolve conflict and there are two fundamental approaches identified: working on understanding the differing viewpoints of protagonists and developing trust. For an executive manager with responsibility for dealing with conflict, it is critical that he or she understands the basis for the differences and has the trust of both parties. Avoiding biases is a critical step to resolving a conflict. While being fair is important, it is also important that the conflict or a specific viewpoint does not lead to a diversion of organisational plans or directions that have been set by an executive manager. 


\section{Delegation}

Delegation involves empowering a subordinate to take decisions for which the executive manager remains accountable. Through delegation (which is the opposite of micro-management), the executive manager shares responsibilities, but more importantly, builds capacity, trust and efficiency in staff members of the organisation. Good delegation requires clear instructions that set out expectations as well as providing feedback on results. Delegation is recognised widely as a most important management practice. It also requires the executive manager to clearly know which decisions and tasks to delegate, when to delegate them and, most important of all, to whom to delegate.

\section{Strategic decision-making}

\section{Dealing with species conservation decisions}

The International Union for Conservation of Nature (IUCN) identifies the primary purpose of a protected area as the conservation of nature. In effect, nature trumps other values, of which there are many. As valuable as other values are, such as tourism or other socioeconomic benefits, they cannot compromise nature. Hence, when decisions may affect a native species or the function of an ecosystem, an executive manager must be cognisant of this fundamental purpose of a protected area. Governing legislation, in any case, provides an overall guideline to all decision-making.

\section{Beyond experience-based decision- making}

While the benefit of experience is invaluable, an executive manager cannot always delay a decision until information gained from operational experience is available. Indeed, executive managers are faced with myriad decisions that have human, fiscal and of course ecological implications. Management must decide. Not taking a decision has repercussions that are equal to taking action. There are outcomes in both instances. Decisions taken with inputs from colleagues, science and socioeconomic considerations overcome shortfalls in experience.

\section{Facilitating the optimum analysis of data}

Quality data are an executive manager's best friend. Good decisions are expedited based on information developed from good evidenced-based data. Quality data, however, require advanced planning as well as a commitment to long-term data gathering. Specific problems require specific data. One cannot solve a park's fiscal budgetary problem, for example, using data on the state of carnivores. Income and expenditure data are needed to address budgetary issues and the carnivore data are needed to manage wildlife species. An executive manager needs to invest in data gathering such as this for the immediate term and, more importantly, for the future.

The costs of data collection may seem exorbitant; however, if it is standardised (consistent data fields) and if it is oriented to address primary objectives, the benefits for protected area management are overwhelming. Without standardisation the risk is adopting methods and data sampling that are not compatible from one year to the next, data are quite useless for long-term monitoring purposes and in effect a waste of resources. It is imperative to invest in the up-front design of replicable data collection. Doing so will assure an optimum analysis of data and decisions made according to evidenced-based information and not perceptions. The prioritisation of data collection will always depend on the main objective of the analysis that has to be made and the main issues that affect the park.

\section{Assessing risk}

Risk assessment calls on an executive manager's judgment about a perceived hazard, its imminent threat status and the extent of the threat. Responses to the threat are based on an assessment of the risk and vulnerabilities. As an example, a forest fire's projected trajectory in relation to a national park facility guides the decision on how to minimise risks, which may consist of evacuating people or changing firefighting tactics. Once assessed, the risk factor is thereafter managed. While fire is used in this example, assessing risk is an element in all decisions affecting a protected area. A large infrastructure project has risks of cost overruns with implications for the park's budget. Furthermore, the implications for not proceeding with the project also require a risk assessment. Promoting one employee over another has human-resource risk implications. Negative implications are at the time inevitable and should not be cause for inaction. Good or bad decisions are evaluated as such only after they are made.

\section{Judgment in decision-making}

Judgment is perhaps the most difficult management attribute to quantify. Yet, judgment - the ability to discern and apply wisdom in decisions - often defines a good executive manager. Judgment is unavoidable whenever uncertainty is involved. Twenty-first-century technology provides access to information at unprecedented levels. 


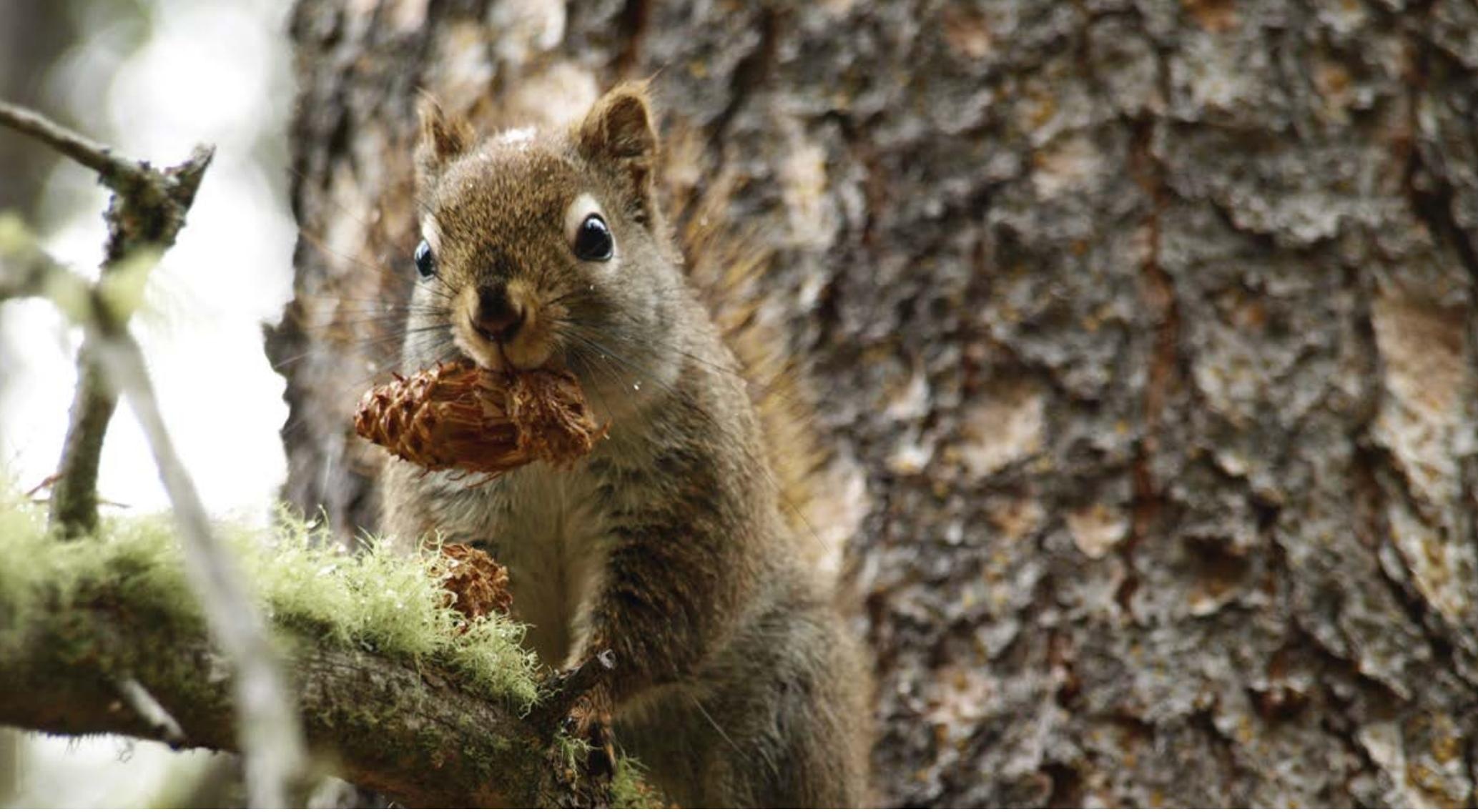

Red squirrel (Tamiasciurus hudsonicus), Banff National Park, Canada: a relatively common mammal found across boreal Canada and in areas up to 800 metres in altitude, and an important part of the biodiversity of this outstanding World Heritage property

Source: Graeme L. Worboys

Yet information, tools, processes or techniques will not yield an answer to management issues. Using these tools, however, helps to make an informed decision that is combined with sound judgment.

\section{Organisational structure, goals and objectives}

The world's many models of protected area organisations and other governance structures for managing protected areas preclude pointing to any one organisational approach as being better than others. There are a number of attributes among these different models that help to assure a successful governing body that meets its goals and objectives.

\section{Defining protected area management goals}

Goals are defined by people with an interest in protected areas. The people in such instances could be indigenous people interested in their traditional lands, politicians, citizens and even tourists from abroad. In all instances, the legislative framework that governs the allocation of land use, occupancy and authority provides the context for goal setting for a protected area agency, be it at a national, regional or community level. A legislative framework in the context of an indigenous or local community may draw on traditional practices or beliefs as a guide to where and what to protect. At the national and regional

levels, the goals might focus on ecological representation of the country, or capturing aesthetic or unique aspects of the country. In all cases, however, for protected areas, the primary purpose is the safeguarding of nature. Other goals - such as provision of visitor experiences, working with neighbouring communities and assuring aboriginal and local community involvement in management-are all important and can be written as additional goals.

The best process of defining organisational goals is through a consultative process that involves staff as well as stakeholders. With an open, consultative process, it is possible to achieve a set of goals that will stand up to scrutiny and time. To be clear, such a process does require effort, incurs expense and requires commitment from political interests and executive managers.

\section{Managing budgets}

The simplest and often the most common approach to budgeting is to follow the previous year's allocations. While simplistic, this is not progressive and absolutely ignores priority setting. Budgets should reflect strategic decisions for a protected area agency—not the other way around. To achieve an organisation's goals and objectives, an executive manager needs to have an adequate budget and human resource capacity. 
Circumstances are often such that budgets require revision. Delays brought on by myriad causes or at times even completion of a project in advance dictate the reallocation of funding. Depending on the governing structure for money management, some funds could be rolled over to the next year, lent to another project as an advance or simply returned to be used elsewhere by the agency. Allocations must be reviewed through the course of a year and increasingly as the year comes to a close. Variance reporting is a critical means of determining fiscal commitments. Audits and other mechanisms such as comptrollers are important as well to assure that funding is used in accordance with approvals. Where budgets are dependent on external sources or project funding, a particular effort needs to be devoted to focusing part of the project on the ways in which to finance the project beyond the allocation.

\section{Measuring accomplishments and success of plans}

Robert Burns, in his poem To a Mouse, wrote that ' $[\mathrm{t}]$ he best-laid plans of mice and men often go awry' (Burns 2004). Organisational plans set out ideas of what should happen for a protected area organisation and identify the goals and the means by which they are to be accomplished. Changes are to be expected as circumstances change for an organisation and unforeseen factors come into play. The reality of change should not deter one from putting considerable effort into consultation with the community and the review and updating of these plans. Also, avoiding input from stakeholders and the community can lead to confrontation.

Organisational strategic plans must be reviewed periodically with a commitment to report on these findings. This is particularly true where protected areas are public lands. Citizens require a periodic report on the intended achievement and whether this was accomplished. Many agencies are producing a 'state of the park report', which is an excellent form of communication with stakeholders. It equally provides for candid exposure to the challenges that a protected area manager faces. Ecological, fiscal and human challenges should equally be featured in any such report. The review of organisational plans is particularly beneficial for preparing subsequent plans where lessons learned can be reflected in the new plan and new directions can be formulated on the basis of past experience.

Canada, presenting the dramatic folded rock sequences of the Rocky Mountains: Parks Canada establishes the goals for managing this worldfamous protected area

Source: Graeme L. Worboys

\section{Efficiency and effectiveness}

Effectiveness is about usefulness, while efficiency is how well one does things. If both are reflected in the formulation of a protected area management plan and carried out accordingly, the protected area in question will be very well managed. To be effective, one needs to think through what needs to be done to achieve a goal. Using the right steps and avoiding trial and error assure efficiency. Training, for example, undertaken in an expeditious and optimal manner is efficient, but if desired change within the organisation is not (consequently) brought about by such training, it is not effective. Another way of stating the difference is that effectiveness is focused on the achievement of objectives while efficiency is the process of achieving the objectives with the least amount of resources.

Patrolling a protected area by one ranger may be as effective as a patrol with two rangers and leads to the conclusion that it is clearly more efficient, if measured by salary expended and time away from other duties. For safety purposes, however, a two-ranger patrol may be more effective should there be difficulty or risk to life encountered along the way. 


\section{Executive management: Working with people}

\section{Moses Wafula Mapesa}

This section emphasises the fact that protected area wildlife managers (executive managers) work with people. It has always been erroneously assumed that wildlife managers work with animals and therefore care about animals more than they care about people. Sometimes the actions and even behaviour of some wildlife managers have lent credence to this argument. Ideally, there should be a balance, and wildlife managers should strive to show they have the same care and concern for people as they have for animals and plants. This includes their own staff, the communities living within or neighbouring their protected areas, the people involved in the tourism industry, politicians, traditional leaders and other government functionaries. All of these categories of people play a role in the fulfilment of protected area management, so the interaction should elicit support and complementary effort as well as stem conflict. Although policies and laws exist regarding the management of protected areas, these should be understood as guiding principles that are subject to change with changing political and legal circumstances and input from all relevant stakeholders, thus reinforcing the need to work with all of these categories of people.

\section{Working with people within the protected area agency}

A protected area agency comprises protected areas and whatever infrastructure and equipment there may be in place as well as staff and their family and dependents. There may also be other people living legally within or regularly coming into protected areas to provide support services to staff and tourists.

Protected area executive managers must therefore, of necessity, establish a working relationship with these people supported by guidelines and guiding principles. Schemes for accessing transport, schooling, medical care, recreation, electricity, water and sewage, waste disposal and shopping must be put in place. A key issue is to control the numbers of people living within or coming into the protected areas, as this has a direct bearing on the management costs and the general protected area environment. Restrictions and policing alone may not be enough in the control of numbers and activities of these people since they are either family or friends of staff or they provide necessary services such as health, education, transport, food and other essentials. Executive managers should engage with these people, appreciate their

\section{Box 12.4 Uganda Wildlife Authority}

The Uganda Wildlife Authority (UWA) is a government parastatal agency. It is semi-autonomous with a board of directors and a CEO. The agency was established in 1996 as a merger between the then Uganda National Parks, established in 1952, and the Game Department, established in 1896. Prior to the 1960s, the key operations of the Game Department were wildlife control and hunting, while Uganda National Parks was responsible for preservation of wildlife and its habitats. Science, working with communities and human resource management became components of the management of protected areas only in the 1960s, 1990s and 2000s. Major policy reforms happened from 1994, leading to the creation of the UWA, which has to date implemented all the changes, making it one of the leading protected area agencies in Africa. The agency employs 1500 permanent staff and more than 500 temporary staff. It is responsible for the management of all wildlife resources in Uganda, including 10 national parks, 12 wildlife reserves and 14 wildlife sanctuaries. The annual budget is about US\$120 million. The board reports to the minister responsible for tourism and wildlife.

supportive role to protected area staff and plan with them how best they can provide services and interact with staff without an undue expansion of numbers in the protected area. Some of the guiding principles may include options for the establishment of staff infrastructure within the protected areas, on the periphery or right outside the protected area, and creatively initiating schemes that address social issues as they arise. All these options will have a cost, as well as ecological and social implications, which must be assessed in line with the IUCN category and management objectives (see Chapter 2) of the protected area. In many cases, it will be prudent to locate staff establishments either on the periphery or outside protected areas to allow for access to existing social amenities and service providers either already outside the protected areas or as they may be planned by local government. Where such options are not possible, however, well thought-out mechanisms for working with people within protected areas need to be developed at the agency level in the form of guiding policies and then implemented.

For harmonious living and to address social issues such as alcoholism, disease epidemics and personal development, protected area executive managers must implement programs that deal with these issues, especially where staff establishments are located inside protected areas. Such programs must be regular and effectively supervised and not left to occasional visits by social workers when 
problems are already well entrenched and are already taking a toll on staff performance (see also 'Staff relations and wellbeing' subsection below).

The people within the protected area agency are very important as their presence and social and infrastructure needs and services in the protected area result in direct management costs and all of this has long-term environmental implications.

To illustrate the point about working with people in a protected area, I would like to share an experience of some protected area colleagues in the Virunga National Park in the Democratic Republic of Congo. The park headquarters was established at Rumangabo on the periphery of the national park in the 1920s. This was to house the administrative infrastructure and accommodation for staff. Staff numbers have continued to grow and so have the numbers of other people living at the headquarters, and infrastructure has expanded. Park management has gone through many cycles of turmoil with the different political forces at play. This has resulted in rather difficult working conditions that have forced the executive management to think critically about the plight of people other than staff, especially their family members and dependants.

Between 2000 and 2012, the park had to house up to 200 widows and family members of former rangers killed in the line of duty. Many more rangers continue to die, leaving behind widows, orphans and dependants. After an incident in 2013, a fellow ranger had this to say about a fallen colleague: 'a Virunga ranger, Paluku Matembela, killed in today's attack, leaves behind a six-month-old son whose mother died in childbirth and their 14-yearold daughter' (Virunga National Park 2014). Chief Warden de Merode had this to say:

At times like this in the past, Virunga's global family has embraced those left behind and I sincerely hope we can all come together again to support those who have paid the ultimate price for defending Virunga National Park. Even in peacetime, life in eastern Congo is incredibly hard, so it is difficult to put into words what a ranger family goes through when they lose the head of their household, a husband, father, and usually a family's only income. (Virunga National Park 2014)

He added: 'We would like to raise enough money for the next five years as part of the Fallen Rangers' Fund commitment to support the families of our staff killed in the line of duty' (Virunga National Park 2014). Virunga National Park set up the Fallen Rangers' Fund to assist

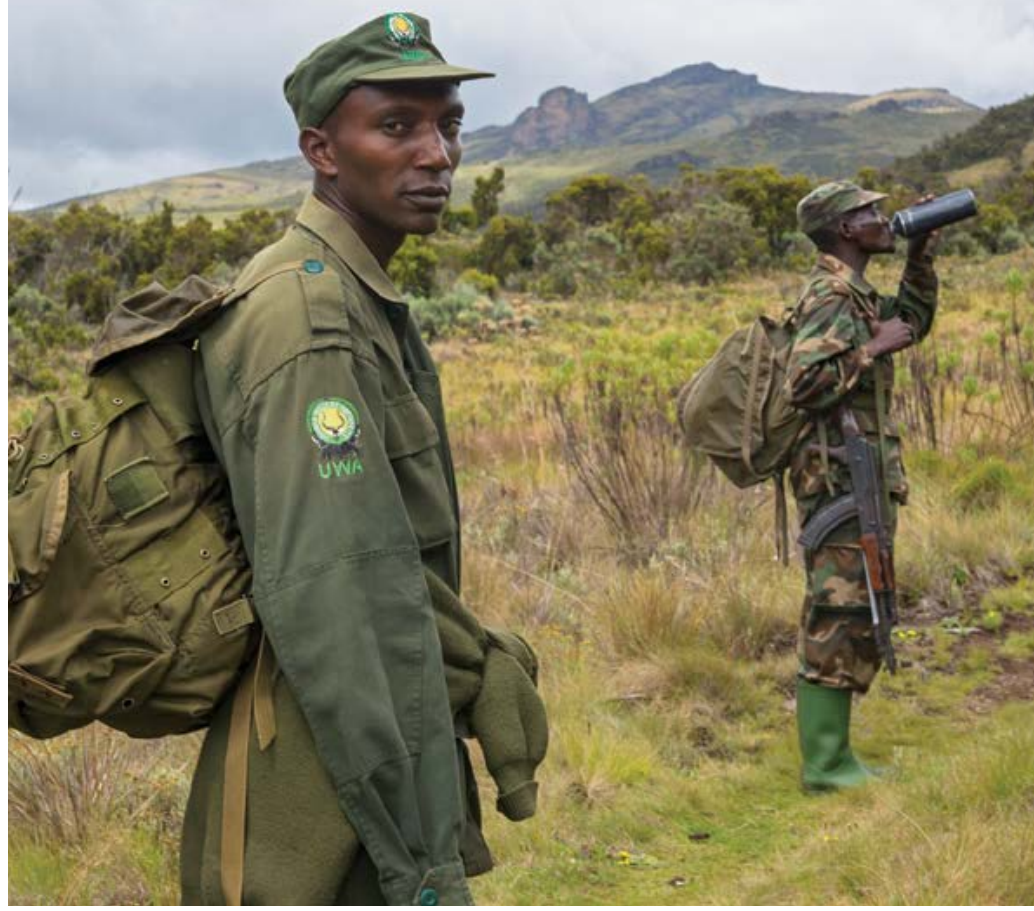

Uganda Wildlife Authority rangers in a highaltitude area of Mount Elgon National Park, Uganda: the park is a transboundary national park with Kenya and is located on an extinct shield volcano

Source: Stuart Cohen

the widows and orphans of rangers killed on duty with start-up funding from donors, private foundations and individuals.

The empathy shown by the chief warden towards the families of fallen rangers has had a powerful boost to morale in the rest of the staff in the park and endeared the community surrounding the park (from where these people hail) to the park management. Of course, the chief's decision is a huge administrative cost; the fallen rangers have to be replaced, and the families of the new rangers require similar support. It is a doubling of the cost; but by creatively coming up with the Fallen Rangers' Fund, the administrative and cost burden has been shifted from park management, and widows and families can be moved out of the Virunga National Park with some start-up capital. It is a win on three fronts.

\section{Working with people in the neighbouring community}

Neighbouring communities are an important category of people with whom to work and interact in managing protected areas. They are neighbours in the first place and in some cases they actually own the land where the protected area is located or they owned it in the past and still lay claim to it. They have a wealth of knowledge about ecology and social interactions over time. In many 
cases, they and their ancestors lived within the protected area ecosystems for hundreds of years before they were reserved. They coexisted with the ecological systems long before contemporary management systems were established. These time-tested management systems/ community norms and traditional knowledge are what the protected area executive manager needs to tap into. Often this is not documented and, even if it were, it would differ from place to place. The community has a wealth of information on errant persons in their midst who are wont to poach, encroach or engage in destructive activities, but they will often be indifferent towards or protective of these people if the working relationship with the protected area management is not mutually productive and respectful or if they feel dispossessed of the protected area's resources.

Recognition of the strong link between neighbouring communities and protected areas must therefore guide and inform the executive manager's working relationship with the community. Often the communities derive livelihoods from the protected areas including direct extraction of products such as food, medicines and construction materials, yet there are restrictions.

Interaction between protected area agencies and communities must not be left to staff in the community conservation departments alone. The protected area manager should regularly interact with communities on topical issues such as resource extraction and use, management zoning, infrastructure development, service provision, monitoring, law enforcement and tourism developments, through dialogue that feeds into planning. Whereas reports from staff and experts may be helpful, regular field interaction adds enormous value, and executive managers must find the time to engage with communities directly. Winning over community support and joint implementation and monitoring of conservation and development programs will be greatly boosted by the direct involvement of protected area managers at a senior level. Such regular interaction will avert conflict and allow for constructive dialogue and negotiation even in the most difficult of situations such as after the loss of property or human life to problem animals.

\section{Working with traditional leaders}

Many communities still have traditional leadership systems that are entrenched within their societies. In such societies traditional leaders wield strong authority and influence over the community. Even where traditional values have been greatly eroded by contemporary systems, there remains vestigial cultural authority held by traditional leaders that is beneficial to conservation and protected area management. This is in addition to the wealth of knowledge in terms of traditional norms that can be reignited such as societies or clans which identify with certain animals, plants or localities that they hold sacred and therefore protect.

Although in some cases traditional leaders can be very demanding, they should not be ignored but rather engaged by executive managers to harness their knowledge, win over their support and work with them to influence the wider community. This takes into account (especially) the cultural aspects that are compatible with contemporary conservation efforts. Traditional leaders and healers can also be powerful as change agents in respect to destructive societal norms such as initiation rituals requiring rare plant and animal parts, and can help in finding substitutes or abandoning or moderating such practices.

\section{Working with political leaders}

Political leaders today assume the role of champions of the people. In many cases, they present themselves not only as representatives of the people but also as the person with solutions to all people's problems. To win an election they will even promise to change laws governing protected areas or to degazette the whole or portions of protected areas to benefit the people. Indeed, many boundary changes have occurred to protected areas and in some cases a protected area's status has changed at the behest of politicians.

In many countries public officers are barred from 'active' participation in politics and therefore when politicians are campaigning for office protected area managers are hard pressed to provide truthful information to an anxious public. In some instances, the public is in conflict with executive managers over the existence of a protected area or use of its resources. Such situations call for strategic thinking and planning by protected area managers well ahead of time and at regular intervals, since the electoral cycle is usually predictable. These situations must be anticipated well in advance and there must be active and non-partisan engagement of key political players and leaders at various levels.

Effective information sharing on protected area objectives and management programs undertaken continuously at various political and leadership levels via documentation and reports, the media, formal meetings and one-to-one engagements have proved to be a useful tool in creating harmony and productive working relationships. Politicians have influence over 
populations, and even when they are unpopular they still influence or make decisions, so there is no room for indifference, failure to engage or for simply ignoring them on the part of protected area managers. Engaging political leaders can be time-consuming as they might simply be out to appease the electorate, and individual leaders change. This engagement is when negotiation skills, effective communication, knowledge of the subject and understanding of the social dynamics have to be put to use either directly by the executive manager or through teamwork and possibly external technical support. By working in this manner, the electoral cycle becomes less disruptive of protected area management while at the same time issues that arise repeatedly can be addressed in a systematic manner through dialogue.

\section{Working with the tourism industry}

When it comes to justifying the existence of protected areas in economic terms, protected area managers often resort to tourism. For many countries, protected areas possess many tourist attractions including unique and spectacular landforms, rare plants and plant communities and a diversity of wildlife. Most protected areas are promoted as tourist attractions. Inevitably, tourist infrastructure is developed in and around protected areas. A key aspect of this is striking the optimal balance between the level of tourism development and conservation objectives. Whereas foreign income is good for national economies and tourism spurs development, it does have an ugly side for both conservation and social norms, which protected area managers should take seriously.

In practice, tourism industry players strive to acquire the best sites within protected areas to gain maximum financial returns. Protected area managers must always remember that conservation is their core and primary responsibility and that tourism development is secondary. Site selection for tourist infrastructure development has to be weighed strongly against ecological as well as aesthetic considerations, not by simply bending to the desires or pressures of often powerful tourism industry players. Scenically attractive sites should not be exclusive but rather should be accessible to all. With protected areas increasingly under development pressure, it is best to locate as few tourism developments and facilities inside protected areas as possible. As with the example of management of staff infrastructure, peripheral tourism developments allow for fewer ecological impacts and social exclusion of workers while enabling staff and their families to access other social amenities. Protected area executive managers should have the capacity to articulate clear management objectives for a given ecosystem and bring out the optimal capacities for tourism developments to enhance both revenue generation and conservation goals. Options for low-impact tourism developments should be assessed, taking into account tourism carrying capacity and cumulative impacts over time. Only when armed with such information can protected area managers professionally negotiate for tourism concessions and monitor them. Tourism developments happen at site level, therefore the direct and firm engagement of tourism industry players by protected area executive managers is essential.

Owing to high economic returns and prospective investments, tourism industry players have access to high-level decision-makers who may be swayed by the economic arguments in total disregard of any environmental considerations. Given this, protected area executive managers should not rely only on ecological arguments in making decisions or recommendations about investments, but should take a holistic approach in assessing a variety of options, which they should share with prospective tourism industry players in a transparent manner, providing the necessary briefs to high-level decision-makers. The limits of acceptable use need to be negotiated based on a scientific approach with inherent monitoring measures. Business skills or sound business advice should inform interaction with the tourism industry in addition to social and ecological expertise.

\section{Working with other government agencies}

Protected areas are found in varied landscapes where other management activities are continuing, and in practice there are linkages with other departments and agencies at both local and national levels. Protected areas occupy land that can often be put to alternative use such as for agriculture, livestock grazing, forestry or for the extraction of resources such as minerals or water. In many instances, the protected area policy and legislative framework exclude any other activity or access to any resources. In other cases, they are inclusive but require collaboration. In reality, there is always debate and a desire to consider alternative land uses, or there are overlaps of mandates depending on the above and below-ground resources in a given area.

There is a tendency for protected area managers to be 'protective' of their areas of jurisdiction, citing policies and laws. Generally, the remote locations of protected areas also limit the regular interaction of managers with other agency colleagues, save for crisis situations. Experience has shown that the protective tendency only 
elicits resentment and conflict from other agencies. In addition, policies and laws are subject to change and indeed changes have occurred to allow for resource access and collaboration depending on the protected area category.

In extreme cases, conflicts have arisen over protected area resources with respective local governments and blame has been levelled against protected area agencies in situations of drought that have led to the deaths of humans and livestock due to shortages in food and pasture, or as a result of crop and livestock raiding by wildlife. Sometimes the issues are access to water or hydropower generation development opportunities or access to timber resources. In other scenarios, the problem is disease and pest control. In such situations, protected area agencies have been blamed for being too conservative, protective and insensitive to the needs of people and uncooperative with sister agencies. Such situations are avoidable by simply working proactively with the relevant agencies to find means of collaborating and creatively addressing the issues without compromising protected area conservation values. Protected area executive managers do not need permission or express instructions in order to engage with counterparts in other agencies, but they should obviously consult with and report to their superiors. If snubbed, they need not despair, but should be consistently resilient and persuasive. The types of collaboration may be broad, stretching to many agencies to include health (in the case of disease outbreaks or risk of outbreaks) and industrial developments (in respect of pollution). So, in practice, it may be tough to draw boundaries for collaborative involvement, however, this is where risk and threat assessment come into play as well as prioritisation based on comprehensive environmental impact assessments/studies at both strategic and site levels. Some of the issues are one-off or temporary, or cyclic such as disease outbreaks, flooding or drought, and may be predictable, thus allowing for reasonable time to consult, share and plan well in advance.

Protected area executive managers must live with the reality that with a scarcity of resources like water, pasture, energy, food and other basic necessities that may otherwise be readily obtainable from protected areas and the growing human population, there will always be a demand both from other government agencies and from people for access to these resources. Therefore collaboration, cooperation and a strong resolve for collective effort in the form of participatory landscape planning with other government agencies, especially at the local government level, are more critical than simply citing and enforcing the law. Again, scientific and cultural information about a given protected area become crucial for all involved to inform the decision-making process on land use or access to resources. Whereas trade-offs may be negotiated, this may only happen in as far as the protected area's purpose and objectives are not compromised.

\section{Leadership: One personal experience}

An experience I would like to share, which could be inspirational to executive managers, happened towards the end of my contract as CEO of the UWA. About one year before the end of my five-year contract as CEO at the UWA in 2009, the term of the Board of Trustees of the UWA was due to expire. I alerted the minister responsible (in writing) three months before the board's term of expiry, drawing attention to the legal provisions of the criteria for the appointment of new members. It was also about the time of the national general election. Despite several official reminders, the board's term expired and no new board was appointed. I worked without a board for nine months. Meanwhile, my contract term was also running out and I drew this to the attention of the minister as well. He responded immediately by offering me reappointment. I humbly protested, advising that he had to first appoint a board of trustees, which in turn would manage the process of hiring a new $\mathrm{CEO}$ or recommend me for reappointment after assessing my performance. The minister wrote to me, officially reappointing me for another five years. Next, he proposed names for board appointments and instructed me to secure their curriculum vitae for submission to cabinet. On scrutinising the $\mathrm{CVs}$, I found that seven of the nine nominees did not meet the prerequisite legal requirements to be appointed to the board. I again respectfully pointed this out to the minister. He ignored my advice and submitted the names to cabinet. At cabinet level, questions arose but the minister was powerful enough to prevail over his colleagues. When the board was announced, there was concern from stakeholders. Once the new board started business it was clear that their sole collective interest was to access funds earned from internal revenue. These funds has been saved and invested over seven years while we had World Bank funding support. The board members needed access to these funds as most were heavily involved in election campaigns at the time.

Now I had to make some hard choices. First, I had been reappointed without following legal process. Second, the board had been appointed without following the legal criteria as stipulated in the Wildlife Act. Third, the board and the minister were determined to fraudulently access millions of US dollars of UWA funds saved 
over seven years. It was clear to me that my fraudulent reappointment was meant to weaken my position. I could have resigned or I could have succumbed to pressure and done as instructed. I chose to stop the looting and re-create order. It was a tall order that nearly cost me my life or life imprisonment, as the minister accused me of treason, among other charges. After trying an internal solution by engaging the minister and the prime minister and failing, I went to the high court and won. The minister was ordered to disband the board and was then transferred. A new board was appointed as per the law and a new CEO hired following proper procedure. The funds were saved. Most importantly, the UWA's protected area programs were not significantly disrupted and, if anything, the UWA has continued to register growth. Although the first two layers of managers were removed (the CEO and directors) as part of the fallout, the third layer was strong enough to collectively 'hold the fort' for the UWA. This institutional strength was due to a deliberate capacity-building effort I had helped put in place during my term. As for me, my contract had expired anyway and I moved on. I look back with satisfaction despite the hard time I went through to uphold acceptable leadership principles.

\section{Staff management}

While I was attending a short course on governance and leadership in Montreal in 2007, the facilitator once said to our class: 'People do not want to be managed. They want to be led.' And he went on to ask, 'have you ever heard of a world manager?' He then answered his own question: 'A world leader, yes; educational leader, political leader, religious leader, Scout leader, community leader, labour leader, business leader-yes to all', and he went on to assert 'they lead; they don't manage'. One can manage a bank, a museum, a protected area and even a home, but when it comes to people, and for that matter staff, what they need is a leader-leadership_-because management is about resource allocation and control.

What, then, do we mean by 'staff management'? It is all about leading staff, providing effective leadership to staff so they can be productive in their respective jobs. There is of course some level of control in the form of guidelines, and resource allocation, to facilitate staff to do their work. So what is entailed in leading staff and what is leadership? Scanning through the literature, there are several definitions of leadership, including the following: 'The ability to achieve priority results through people; the ability to move yourself and others towards who you want to be; asking the right questions and inspiring others to work through individual and collective action as opposed to instructing them on what to do' (D’Souza 1994).

The heading for this section could have been 'leading staff', but for the sake of conventional wisdom, the terminology 'staff management' is used. Jon Jarvis has described leadership in some inspiring detail. Here I wish to focus on staff leadership. Staff leadership (or management) is about team building, staff welfare and relations, capacity building, professional development, mentoring, understanding different types of people and cultures and industrial relations.

\section{Teamwork}

Ordinarily, teamwork is about a group of people who agree on what they would like to achieve, they have or subscribe to a vision and a mission and they go ahead to set goals and define the desired results. They then decide how they want to attain the desired results. Every team must have a leader and every team must have guidelines. Resources must be available, roles clearly spelt out and accountability forthcoming. At the end of every effort, there will be consequences both positive and negative, depending on the level of attainment of the desired results. The leader must be quick to recognise weaknesses in the team and either help the weak members improve or replace them.

Teams are built, and it takes time and careful selection to build winning teams. Characteristics of teams include the following.

- An assemblage of top-class people. They must be qualified with skills in different but complementary fields, intelligent, trustworthy, with diverse perspectives and some of them with experience. In practice, there are always several teams that come together to form one great team. Protected area managers will, for instance, have teams in community conservation, finance, law enforcement, tourism, engineering, and so on-all coming together to form one great team for the protected area. Individual protected areas then come together to form an even greater team for the agency.

- Guidelines must be in place but must also allow for flexibility. It is pointless to hire intelligent people only to take away the opportunity for them to be creative and to take the initiative.

- Each team must have a leader who must have a vision or be committed to one, which is shared by the team members. The leader must allow for creativity but should also be a shield in the event that some of the novel ideas backfire. 
a protected area executive manager to experience and check out welfare needs such as medical provisions, food rations, camping gear, uniforms and transport. It is not enough to rely on written reports and policy guidelines, and it is useful to regularly check if practice is in line with policy and if management plans are being implemented. The interaction also allows for feedback that helps in management planning and policy reviews.

Obviously there will be cases of carelessness, omissions and mistakes among staff-some grave enough to be of a criminal nature-but the handling of these must be in conformity with policy guidelines, operating manuals, and labour and other relevant laws. Malice, backstabbing, favouritism, nepotism and other negative vices are bound to occur; an executive manager must always check the facts, hear out the victim and offer a chance for reform.

Social welfare arrangements/provisions/schemes are critical for staff loyalty and productivity. Such arrangements should, as much as possible, cover immediate family members, especially in countries where public social services are poor. Such schemes may include medical insurance, education, transport and housing. These schemes, in addition to competitive salaries, mitigate against corruption, embezzlement and fraud, and misuse of equipment. They also improve relations with the wider community neighbouring the protected area as some of them will access the services directly or indirectly and some of the staff will come from or retire into this community. This may reduce conflicts and the occurrence of illegal activities or enhance cooperation in addressing these issues.

Another aspect of staff welfare is motivation. Having a creative and free working environment is a motivational factor, as are attractive staff welfare schemes; however, the personal performance of individual staff needs to be recognised and there are many ways to do this. Recognition can also be given to teams, but even then each individual team member should receive a personal accolade. Recognition could include letters of commendation, certificates, awards, holiday offers, gifts, bonuses, further training opportunities, salary increments and promotions_consistent, of course, with organisational guidelines.

\section{Learning from failure: A protected area ranger's experience}

In 1993, as a new law enforcement warden in Kidepo National Park in Uganda, I was confronted with the challenge of large numbers of artisanal goldminers coming into the park with livestock. They also engaged in poaching. I planned and implemented three ranger patrols to address the problem, all of which failed. I led the third patrol myself, and one evening an elderly ranger asked me what I would do if the ongoing operation failed just like the previous two. I instinctively responded that we would 'celebrate' the failure and think again - in other words, try to learn from the three failures and plan again, as a way of keeping morale high. In fact, I was considering disciplinary action against the patrol leaders. True to the ranger's fears, we found lots of people, mainly women and children, involved in the artisanal goldmining, lots of livestock attended to by a few young men and the carcasses of freshly poached kudu and ostrich. We 'arrested' more than 150 people-threequarters were juveniles and women. As with the past two operations, we cautioned and released all of them since we had no capacity to move them even to the park headquarters (90 kilometres away) or the nearest police station (150 kilometres away). The backlash from these three failed operations included accusations by the police, local leaders and the community that park management was harassing 'innocent' locals mining gold for survival and that we had illegally confiscated large quantities of gold. I had almost believed the same allegations against the rangers and had considered disciplinary action before I chose to lead the third operation myself. Meanwhile, the communities mobilised in even larger numbers to go into the park, and armed themselves with automatic rifles since they had been emboldened by their leaders. This is when we chose to review our failures, decided against any disciplinary measure and, in a 'celebratory mode' (local brew and food were served with a local musical performance), invited all the rangers to contribute ideas on how to address the problem.

In summary, we agreed that the reasons the park was being invaded were a prolonged dry season, which meant there was no food, an externally driven incentive for goldmining by a licensed company operating outside the park, but most importantly, the operational mistakes of releasing those arrested without involving local leaders and the police while confiscating all their tools. So in the fourth operation, all the local police chiefs and local leaders were ferried to the site, and rather than confronting the communities with the law, we engaged in dialogue to find out why they had invaded in large numbers and worked out the solutions together. After four days of dialogue, it was agreed that the artisanal goldmining in the park must stop, and with it the poaching and livestock grazing, but park management would help access food from the World Food Program 
that was supplying food in the region anyway. Persistent offenders would be arrested and charged by the police with the full knowledge of the local leadership.

\section{Capacity building}

Capacity building is a continuous process through one's career because we live and work in a changing environment-ecologically, economically, socially and technologically. Staff must have equal opportunity for capacity-building programs, both in-house and external. Capacity-building programs must aim at enhancing competencies and skills for better performance as opposed to earning promotions. In many countries, after undergoing capacity-building programs, some staff erroneously demand promotions or bigger assignments, which they may not yet be ready for or which may not even be available in the agency. This often results in staff leaving the organisation at the expense of the capacity-building effort. Staff retention schemes must therefore be put in place and emphasis must be placed on performance enhancement in existing placements.

\section{Training programs and professional development}

Staff have an inherent desire for academic and professional growth at varying levels. This should be encouraged and supported. Staff who manifest this characteristic are relatively easier to handle because they presumably have an interest in improvement. They will, however, also need guidance so that the desire for improvement is not overridden by ambition to reach the top too quickly. Such staff may be good candidates for long-term research programs that create or add knowledge. Those who do not exhibit the desire for improvement may be encouraged to take on shorter competency or vocational skills-based training. For better results, staff undergoing training programs for professional development should be allowed reasonable time for training in their position in a protected area. Immediate personnel requirements sometimes disrupt such professional development programs. Agencies could hire short-term staff for temporary and urgent manpower requirements rather than disrupt ongoing professional development programs. Professional development programs should aim at filling critical gaps in the agency to address specific management requirements such as responding to climate change issues as they may impact on protected area management and for disaster risk reduction.

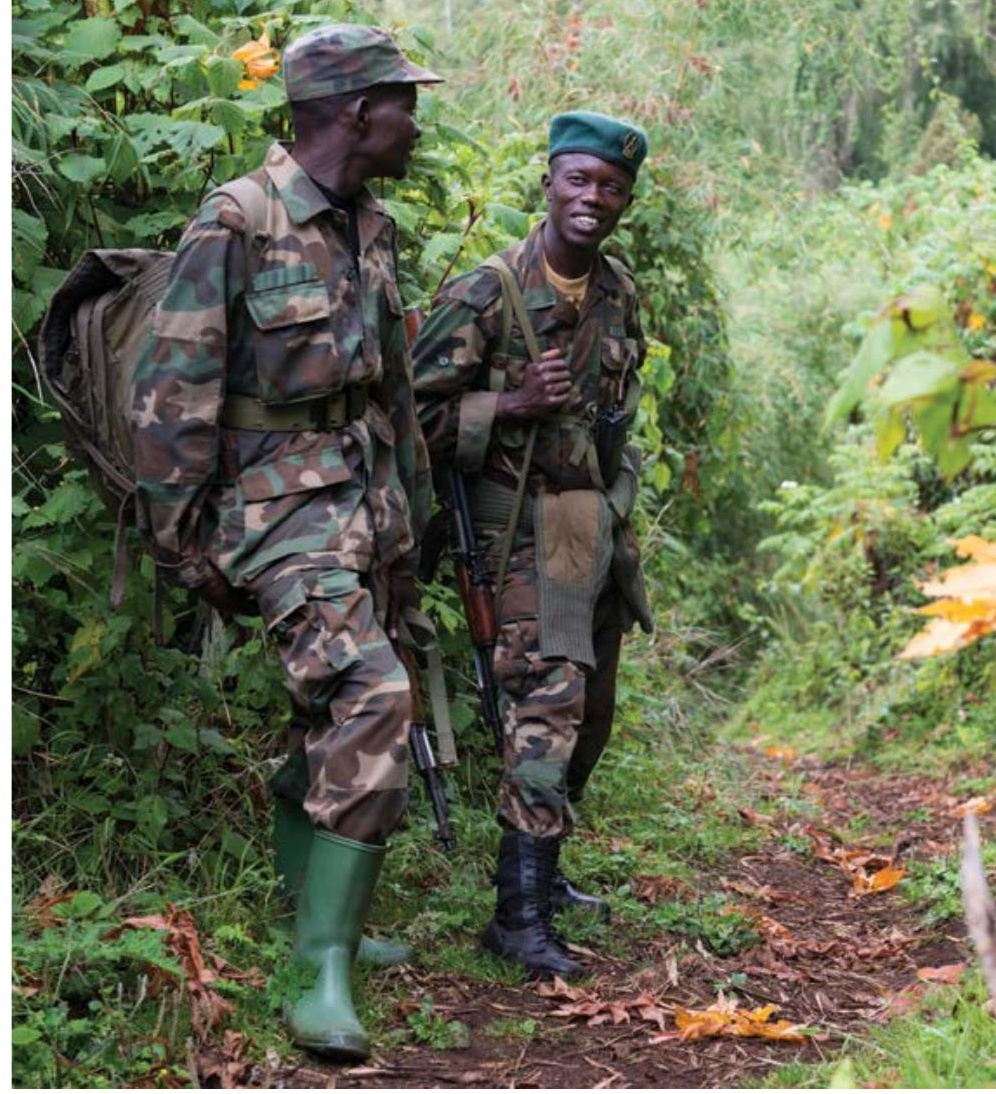

Uganda Wildlife Authority rangers on patrol in a forested area on the lower slopes of Mount Elgon National Park, Uganda

Source: Stuart Cohen

\section{Mentoring and acting opportunities}

In any given protected area management scenario, staff will time and time again be away from their positions for various reasons and key positions will fall vacant that may not immediately be filled. Prudent leadership requires that such scenarios be anticipated and mechanisms built to address them. Deliberate efforts have to be undertaken to nurture and mentor staff to act in the absence of executive managers for short periods or to ultimately fill such positions when the need arises within the agency or elsewhere.

Care must be taken to ensure that mentoring and acting assignments do not overburden the beneficiary. An effective mentoring approach is delegation. In such a relationship, everyone must be clear on the purpose and direction, and guidance must be forthcoming from the supervisor/mentor. Trust and commitment are essential and a sense of optimism-an 'I can do it attitude'-is important for the beneficiary. Mentoring, to a large extent, enhances the effectiveness of the supervisor, increases the productivity of the unit and develops the professional capacity of the staff. Mentoring is achieved through the assignment of tasks. When such tasks are assigned, the mentor transfers the task with very clear objectives and requirements; passes on the authority needed to perform the task; allows for flexibility; and when completed, provides acknowledgment and credit for success. This provides an opportunity for 
the development of staff; however, the mentor retains control, accountability and benefits from the support of the staff being mentored.

In protected area systems, the protected areas are spread out geographically and in some instances are very large, so in practice executive power has to be delegated to site or section-based managers. This means a mentoring process is always ongoing. The executive manager supervisors, however, have to be alert to this fact and rather than trying to keep the authority at the protected area head office they should devolve it to the sites and provide guidance. A successful mentoring process should ideally result in a three-layered executive leadership model and practice at all levels in the agency. The three-layered leadership model ensures a clear hierarchy in leadership roles with decision-making authority. The effect is that there will always be a stand-in officer (acting assignment) in the event that the top two layers are away for whatever reason.

\section{Understanding culture and different types of people}

Cultural practice forms an identity for different types of people. One can read about different cultures and different people and gain very useful insights. A key aspect of understanding different cultures and different people is to realise and accept that differences exist. A positive attitude and a desire to understand rather than influence, impose or abuse the different cultures and peoples are required. The simple rule is that 'no culture is superior and no culture is better-period'. Culture and people are in a continuum of change and it is best to appreciate the spontaneity of change even when influence has to be exerted.

A simple, practical and powerful way to understand different cultures and different people is to engage in conversation and interact with them informally. Attending informal (and formal) functions in a given locality and especially honouring personal invitations, even for lunch, tea or an evening drink, afford a very good opportunity to understand culture and people.

Elderly people I have engaged in conversation have argued that in this day and age, when problems are increasingly complex and there is no simple cause and effect, one cannot imagine how stressful it is to be a leader and to pretend to have all the answers. An affirming leader is one who knows how to rely on and use the art of conversation that exists everywhere in communities. These leaders act as hosts and stewards of other people's creativity and intelligence. This kind of leader does not give us the answers but gathers us together so that together we can discover the answers.

By respecting different cultures and peoples, one is able to defuse conflict, win over support and learn about many aspects of nature conservation in all parts of the world, for culture and conservation have always been intertwined and have continued to evolve amid new developments. All peoples have a rich culture, which when understood and respected (you do not have to believe in it), has inherent and effective conservation mechanisms. It is the reason there is so much talk early in the 21 st century about indigenous knowledge and working with communities; the reason also the UN Educational, Scientific and Cultural Organisation (UNESCO) recognises the link between culture and nature, and why increasingly, many World Heritage properties are referred to as mixed properties that embed both cultural and natural outstanding universal values.

\section{Industrial relations}

Industrial relations is the link between employers (owners of business or enterprises) and employees. In many cases, this results in a third-party arrangement to broker relations between employees and employers to benefit staff development and guarantee conducive working terms. In practice, sometimes employers resent the third-party arrangement in the form of trade unions, but in protected area governance arrangements, employees usually serve governments and there are designated boards, trusts or commissions that serve the role of employers. Private protected areas and community conserved areas, however, now exist and have the potential to grow. Accordingly, there are statutory arrangements in place that provide guidelines on employer-employee relationships.

What is important under industrial relations is recognition that third-party arrangements give a voice to employees and serve as a practical and useful tool for checks and balances that ensure statutory provisions are being followed. They also allow for creativity for enhancing productivity and staff wellbeing. Such staff support schemes may include access to personal loans for individual staff development, healthy living counselling (HIV, alcohol, drug abuse), career guidance, retirement and social responsibility clubs. Interestingly, there are many examples of senior officers in agencies who shun industrial relations arrangements or even stifle their existence or operations only to fall back on these staff support systems in times of personal trouble. 
inclusivity, guidance and coaching much more than directing, which is now often the norm. The leader must avoid solving problems with an 'I am the boss and I have the answers' approach, but rather on the basis of listening and deciding accordingly. To be sure, leaders in the future will still need to be decisive; however, a decision becomes easier to make when the leader instils a culture that empowers individuals and thus encourages creativity. The need is for a leadership style of openness with clear ethical values. Overarching bureaucracies and the paramilitary organisations of the past will not be nimble enough to survive the rapid changes that are expected to shape our future.

An overriding consideration in all of the above is that leading a protected area agency is one of the most noble and satisfying callings. Protecting nature for future generations and helping people to discover themselves through contact with nature are but two of myriad benefits that are derived from leading a protected area High-altitude flora, Mount Elgon National Park, Uganda

Source: Stuart Cohen

\section{Conclusion}

\section{Julia Miranda Londoño}

What is the future for leaders of protected areas? Most likely, it will be one of increased instability. Changes in the operating environments of protected area agencies can be expected to be rapid and abrupt. Climate is but one anticipated driver of such change. Biotechnological advances such as DNA manipulation are poised to challenge the definition and authenticity of natural environments that are the raison d'être of protected areas. The global reach of communications through the Internet can instantly build up or destroy the reputation of protected area agencies, which can carry significant repercussions for revenues and government decisions. Demographics are another driver of change, albeit at a somewhat slower rate; within some countries mean ages increase while in others they decrease. Unparalleled levels of urbanisation around the globe and with them an increasing segment of people without personal contact with nature present an increasing dilemma for future, if not present, managers to face. To survive in the future, organisations and their leaders must learn to adapt continuously to what will be an increasingly volatile environment.

Managing within the complexity of the future is a leader's challenge. The future will require, more than ever, a team approach that encourages bottom-up rather than hierarchical top-down approaches. To provide leadership in this milieu puts the onus on listening, agency. Protected area leaders must give voice to the voiceless: those who came before and charged the leaders of today with this responsibility by leaving a legacy of conservation; those of the future, who expect that we will give them a natural world within which they will want to live; and nature itself, which cannot speak when decisions are being made about its future. Drawing inspiration from these responsibilities can only help to provide responsible leadership that avoids corruption, abuse of rank, myopia and ignorance, which could undermine leaders and the very organisation they are asked to lead.

Before ending this chapter, I would like to present case studies of the work of two outstanding protected area leaders with whom I have had the pleasure of working. One describes the outstanding work of Fabio Villamizar Durán from my home country of Colombia (Case Study 12.1) and the second is about the excellent work of my IUCN World Commission on Protected Areas (WCPA) colleague Andrej Sovinc, in Slovenia. Andrej is the head of Sečovlje Salina Nature Park in Slovenia and Deputy Director of Soline Salt Making Limited. He is the protagonist of the story he tells (Case Study 12.2). These two case studies help to demonstrate the importance of leadership in managing protected areas and what may be achieved when there is great clarity of direction, purpose and initiative combined with perseverance, tact and a desire to protect Earth's nature and culture. 


\section{Case Study 12.1 Leadership in Colombia}

Fabio Villamizar Durán has headed the North-East Andean Regional Division of National Park Service of Colombia, where eight national parks are located, for nine years with exceptional leadership. In 2014, aged 53, Fabio is an economist specialised in finance and telecommunications management and regulation. He manages to undertake his functions both within and outside the organisation, with an innate exemplary leadership.

Within National Parks, he works directly with the park managers and their staff, knows their jobs closely and is in control of the on- ground reality of the protected areas. He provides confidence to his staff, shows interest in their personal situations and supports them, and at the same time he is rigorous and demanding. They undertake planning together, define the strategic lines and establish operational plans to address important issues such as land tenure and control by the state, restoration, environmental law enforcement, research, monitoring and control and surveillance, with an approach that promotes community participation, which he has developed through a close relationship with peasant families and indigenous communities. He arranges constant follow-up and evaluation meetings to measure progress. His priority 'is the protected areas that are the reason for the institution to exist; we are devoted to them, and they need all our support'. 'There is no room for doubt or apathy', he says. tenure and subsequent land restoration-one of the most demanding problems faced by the parks in Colombia. He has built projects with international cooperation, with local and regional governments, as well as with private companies for more than US\$50 million to accomplish this.

Fabio has gained respect and recognition in other public institutions both in his region and at the national level, because of his highly qualified, technical and serious work. He actively participates in regional land-use planning processes with other public agencies and private entities by providing a joint and articulated view and getting them involved and convinced about the importance of conservation.

He has participated in conservation strategies with páramo landscapes, fostering creation of regional protected areas, participating in climate change discussions, land-use planning and in promoting the recognition of indigenous communities' rights. His strategy has been one of generating trust based on an ample knowledge of his region, always making use of solid arguments, persuasion and negotiation skills to interact with potential donors. Fabio's first concern is to satisfy the needs of the protected areas rather than the donor's wishes. The results of his work are crucial and undeniable for the whole country.

Fabio has developed innovative and very successful initiatives to raise the money required to undertake studies, buy the properties within parks that are under private

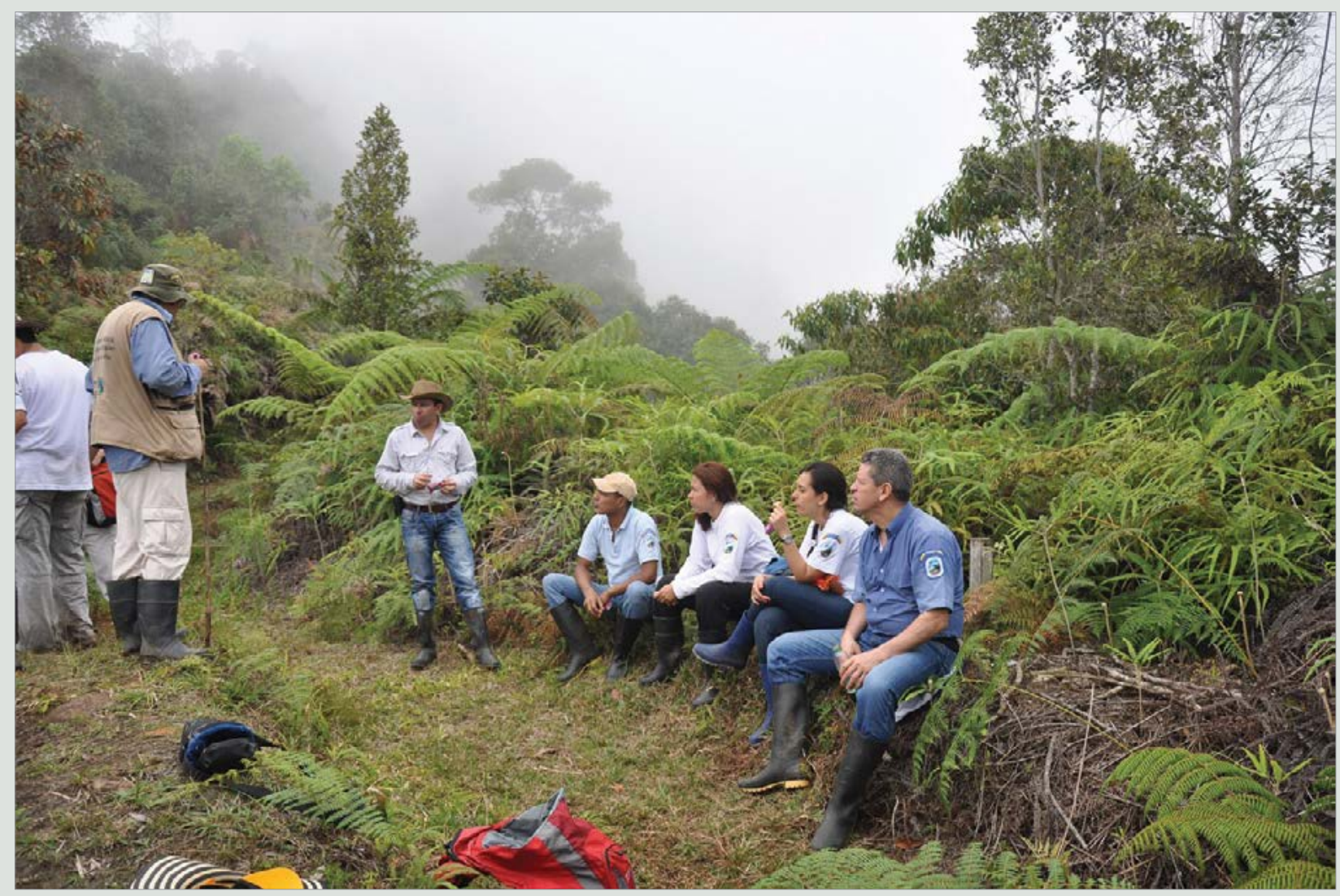

Fabio Villamizar Durán (far right), North-East Andean Regional Division, National Park Service of Colombia, and staff resting during a protected area field inspection

Source: National Parks Service of Colombia 


\section{Case Study 12.2 Leadership and executive management in Slovenia}

The Sečovlje Salina Nature Park is situated on the Adriatic coast in the northernmost part of the Mediterranean Sea. It covers more than 6.5 square kilometres and is considered one of the most important natural and cultural heritage sites in Slovenia. It is designated an IUCN Category V Nature Park, Ramsar site, Natura 2000 site and a cultural monument of national importance. The area is known as one of the key biodiversity hotspots in Slovenia. Sečovlje Salina Nature Park is home to some 300 bird species, several salt-loving plants and endangered habitat types, which are dependent on the highly saline environment.

Sečovlje Salina represents one of the last traditional saltpans in the Adriatic Sea. Due to difficulties in the European salt market following the arrival of salt produced mainly in North Africa, where the production costs were lower, the majority of traditional saltpans in the northern Mediterranean were abandoned after World War II, and transformed into mass-tourism destinations or urban areas, or used for aquaculture. This almost happened in Sečovlje-traditional salt-making processes were almost stopped by the end of the 20th century.

A major change happened in 2002, however, when the company Soline, with the licence for production of salt, was bought by a mobile phone company. Soline has a specific status in terms of management of the stateprotected Sečovlje Salina Nature Park. The company has been given a concession, issued by the Government of the Republic of Slovenia, by which the company is responsible for management of the nature park and the use of its natural resources. All the land and properties in the park remain state owned.

The new owner of the company divided its activities into commercial (traditional salt-making and tourism) and the implementation of the public service of nature conservation (management of the park, including visitor management). New products, based on purely artisanal salt, rich in minerals, were developed and new target groups of buyers were approached. More than 25 basins for traditional salt production were restored, together with basic infrastructure for visitation. Salt is again being produced using 700 -yearold methods and is now available in several countries, from Japan to the United States and across Europe. The marketing skills of the mobile phone company were used to develop, promote and sell the traditional salt product.

Active management of the park and its promotion increased the number of visitors by more than six times in the past 10 years. Sečovlje Salina is now considered to provide added value for ecotourism development for the community of Piran-the most developed tourism community in Slovenia. Parts of the saltpans are strictly protected areas, provided for the maintenance of favourable ecological status for several endangered habitats and species. No commercial activities are allowed in these areas and even visitation is limited and strictly controlled. Population trends in recent years for the key biodiversity indicator species are stable or even increasing. Key support for biodiversity conservation in the park is sought from EU funding programs, especially LIFE projects.
The number of employees of Soline has risen from 16 workers in 2002 to more than 90 in 2013. There are more than 30 additional seasonal jobs offered during the summer. There are direct and indirect benefits in this public-private partnership. The mobile phone company decided to invest in protection of nature and cultural heritage in Sečovlje to generate direct benefits by selling salt and collecting fees from park visitors and those attending specific programs for the visitors of the park (for example, the 'Become a Salter for a Day' program). The company also plans to invest in development of major tourism infrastructure outside the park area.

Even more important benefits for the company in this joint venture are indirect. The company's corporate reputation has improved: several customers expressed their appreciation of its environmental responsibility investing in the protection of natural and cultural heritage, and thus became the company's clients.

One should not forget that this model of state-delegated management would not be possible without the involvement of senior managers of Soline who have high personal regard for conservation and awareness of the importance of the preservation of cultural heritage and tradition.

Experience in the creation and management of the Sečovlje Salina Nature Park demonstrated that commercial activity (traditional salt-making and tourism) can coexist with the requirements of the protection of nature, cultural heritage and tradition in the nature park. Conservation efforts are also seen as an added value both for the development of sustainable land-use practices and for the provision of benefits for the local community.

- Andre Sovinj

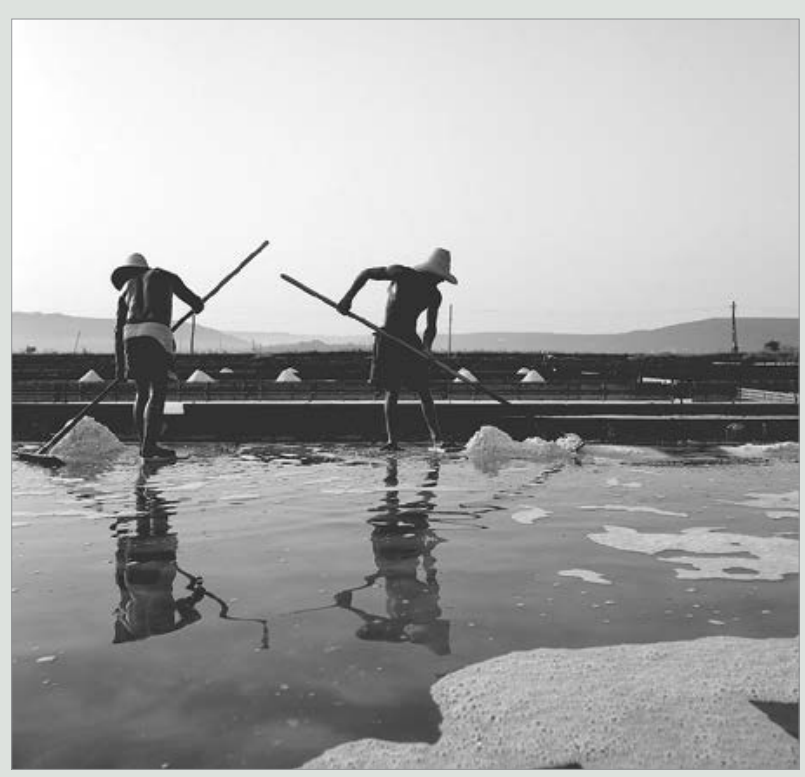

Traditional salt harvesting, Sečovlje Salina Nature Park, Slovenia

Source: Andre Sovinj 


\section{References}

Decommended reading

Dd Abrashoff, D. M. (2001) 'Retention through redemption', Harvard Business Review 79(2): $136-41$.

Dd Bartol, K., Martin, D., Tein, M. and Mathews, G. (1998) Management: A Pacific Rim focus, McGraw-Hill, Sydney.

Dd Bazerman, M. (1998) Judgement in Managerial Decision Making, 4th edn, John Wiley, New York.

Burns, R. (2014 [1786]) 'The best-laid plans of mice and men often go awry', The American Heritage New Dictionary of Cultural Literacy, 3rd edn, [Online]. <dictionary.reference.com/browse/thebestlaidplansofmiceandmenoftengoawry>

D’Souza, A. (1994) Leadership: Trilogy on leadership and effective management, Kolbe Press, Limuru, Kenya.

Heifetz, R. A. and Laurie, D. L. (2001)

'The work of leadership', Harvard Business Review 79(11): 131-41.

Dd Heifetz, R. A. and Linsky, M. (2002) 'A survival guide for leaders', Harvard Business Review 80(6): $65-74$.

Dd Heifetz, R. A., Grashow, A. and Linsky, M. (2009) 'Leadership in a (permanent) crisis', Harvard Business Review 87(7-8): 62-9.

Leopold, L. B. (ed.) (1993) Round River: From the journals of Aldo Leopold, Oxford University Press, New York.

Parks Canada (2012) Corporate Plan 2012-2013/20162017, Parks Canada, Gatineau, Quebec.

Dobbins, S. P. and Coulter, M. (2005) Management, 8th edn, Prentice Hall, Englewood Cliffs, NJ.

Dobbins, S. P., Bergman, R., Stagg, I. and Coulter, M. (2003) Foundations of Management, Prentice Hall, Sydney.

Dd Stayer, R. (1990) 'How I learned to let my workers lead', Harvard Business Review 68(6): 66-83.
Taylor, W. C. (1999) The Leader of the Future: Harvard's Ronald Heifetz offers a short course on the future of leadership, Fast Company \& Inc. $<w w w$. fastcompany.com/37229/leader-future>

Virunga National Park (2014) Rebels Attack Ranger Patrol, Killing Three, Virunga National Park Archives, Democratic Republic of the Congo. $<$ virunga.org/archives/rebels-attack-ranger-patrolkilling-three/>

Wheatley, M. J. (2006) Leadership and the New Science: Discovering order in a chaotic world, Berrett-Koehler Publishers, San Francisco. 
This text taken from Protected Area Governance and Management,

edited by Graeme L. Worboys, Michael Lockwood, Ashish Kothari, Sue Feary and Ian Pulsford, published 2015 by ANU Press, The Australian National University, Canberra, Australia.

Reproduction of this ANU Press publication for educational or other non-commercial purposes is authorised without prior written permission from the copyright holder, provided the source is fully acknowledged. Reproduction of this publication for resale or other commercial purposes is prohibited without prior written permission of the copyright holder. 